\title{
EFEK TEPI KORIDOR JALAN DI HUTAN BUKIT POHEN, CAGAR ALAM BATUKAHU, BALI
}

\author{
Dini Fardila* dan Sutomo** \\ *Program Studi Biologi - UIN Syarif Hidayatullah Jakarta \\ **UPT - BKT Kebun Raya "Eka Karya" Bali \\ E-mail: sutomo01@student.uwa.edu.au
}

\begin{abstract}
Road corridor has been known to have an influence on the microclimate and vegetation condition along the forest edge which directly bordered with the road. This study was conducted in order to obtain information regarding the depth of edge influence which can be seen by the changes in microclimate and vegetation condition from forest edge to interior in Pohen Mountain, Batukahu Nature Reserve Bali. Microclimate variables such as light intensity, wind velocity, temperature and relative humidity, and vegetation variables such as basal area, tree height, density and number of species were measured on two $100 \mathrm{~m}$ transects perpendicular from forest edge to interior. The correlation between microclimate and vegetation condition with distance from the road was analyzed by using MANOVA and ANOVA. The depth of edge influence was estimated by using Principal Component Analysis (PCA) ordination. Microclimate showed significant correlation with distance from the road to forest interior $(r>0.5, p<0.05)$. Light intensity, temperature and wind velocity tends to decline as we move towards the forest interior and the reverse was true for the relative humidity. Microclimate gradient changed sharply until it reached the distance of $40 \mathrm{~m}$ from the forest edge. For vegetation parameter only the height of trees which was significantly correlated with the distance from the road. PCA analysis showed that the depth of edge influence for the microclimate condition was clearly showed up until $40 \mathrm{~m}$ from the road. This result suggests that forest buffer area with minimum width of $40 \mathrm{~m}$ is needed to protect the forest interior of Pohen Mountain from the exposed microclimatic condition of the edge area.
\end{abstract}

Key words: Batukahu Forest, microclimate, edge effect, road corridor

\section{PENGANTAR}

Rencana pembangunan Pembangkit Listrik Tenaga Panas Bumi (PLTPB) Bedugul hingga saat ini masih menuai pro dan kontra. Terlepas dari manfaatnya dalam memenuhi kebutuhan listrik di Bali, pembangunan PLTPB Bedugul yang dilakukan di kawasan Cagar Alam (CA) Batukahu dikhawatirkan akan memberi dampak negatif terhadap integritas ekosistem di kawasan konservasi ini. Pembangunan jalan beraspal sebagai infrastruktur PLTPB Bedugul yang membelah Bukit Pohen, salah satu bagian dari kawasan CA Batukahu, menyebabkan hutan Bukit Pohen terfragmentasi.

Koridor jalan yang dibangun melintasi hutan menyebabkan daerah tepi hutan yang berbatasan dengan jalan mengalami dampak dari pembukaan jalan tersebut. Salah satu dampak koridor jalan terhadap tepi hutan adalah adanya kondisi mikroklimat yang berbeda, terutama yang terkait dengan cahaya matahari dan angin, di perbatasan tersebut (Davies-Colley dkk., 2000). Kondisi mikroklimat yang berbeda di perbatasan menyebabkan tepi hutan mengalami efek tepi (Forman, 1995). Efek tepi adalah perbedaan dalam faktor biotik atau abiotik yang terjadi di perbatasan dari suatu fragmen habitat relatif terhadap daerah interior habitat tersebut (Gehlhausen dkk., 2000).
Efek tepi dapat terlihat dari perubahan gradual mikroklimat serta pola vegetasi dari tepi hingga ke interior hutan. Efek tepi dapat mempengaruhi struktur, fungsi dan komposisi hutan, dan bahkan mengarah pada degradasi fragmen hutan (Harper dkk., 2005).

Sejauh mana efek tepi terjadi pada suatu fragmen habitat dapat diestimasi dengan mengukur kedalaman efek tepi atau depth of edge influence (DEI). Chen dkk. (1995) mendefinisikan DEI sebagai jarak dimana masih terjadi perubahan dalam nilai suatu variabel yang diukur sebelum akhirnya variabel tersebut menjadi konstan seiring dengan pertambahan jarak dari tepi ke interior hutan. Dengan mengestimasi DEI di hutan Bukit Pohen, dapat ditentukan lebar daerah penyangga hutan yang dibutuhkan di kawasan CA Batukahu untuk melindungi kondisi ekologis interior hutan dari paparan mikroklimat yang berbeda di tepi hutan akibat adanya pembukaan jalan.

\section{BAHAN DAN CARA KERJA}

\section{Waktu dan Lokasi Penelitian}

Penelitian dilakukan selama bulan September hingga Oktober 2010 di hutan Bukit Pohen. Hutan Bukit Pohen merupakan salah satu bagian dari kawasan Cagar Alam Batukahu. CA Batukahu terletak pada koordinat $8^{\circ} 10^{\prime}-8^{\circ} 23^{\prime}$ 
LS dan $115^{\circ} 02^{\prime}-115^{\circ} 15^{\prime} \mathrm{BT}$, dan secara administratif terletak di Desa Candikuning, Kecamatan Baturiti, Kabupaten Dati II Tabanan, Bali. Hutan Bukit Pohen memiliki luas 388.2 ha dan berada pada ketinggian 1520-1600 mdpl dengan kemiringan tanah $5-35^{\circ}$. Koridor jalan yang membelah hutan menuju PLTPB Bedugul merupakan jalan beraspal dengan lebar sekitar $4 \mathrm{~m}$.

\section{Metode Penelitian}

Pada lokasi penelitian dibuat dua transek garis sepanjang $100 \mathrm{~m}$ tegak lurus dengan tepi jalan. Jarak antar transek yaitu $50 \mathrm{~m}$. Pengukuran variabel mikroklimat dilakukan di sepanjang transek garis pada enam titik sampel, yaitu titik 0 (tepi), 10, 30, 50, 70, dan $90 \mathrm{~m}$ (interior). Analisis vegetasi pohon dilakukan pada lima plot ukuran $20 \times 20$ $\mathrm{m}$ yang dibentangkan tegak lurus transek garis pada titik 0, 20, 40, 60, dan $80 \mathrm{~m}$.

Variabel mikroklimat yang diukur meliputi intensitas cahaya, kecepatan angin, suhu udara, dan kelembaban udara relatif. Variabel mikroklimat diukur pada setiap titik sampel dengan pengulangan sebanyak dua kali. Kesemua variabel mikroklimat diukur pada pagi hari antara pukul 9.00-11.00 WITA. Variabel vegetasi yang diukur meliputi luas basal yang dihitung dari diameter setinggi dada (dbh), tinggi pohon, kepadatan dan jumlah jenis pohon.

\section{Analisis Data}

Variabel mikroklimat dan vegetasi pohon dimodelkan dalam grafik untuk melihat hubungan antara jarak dari tepi jalan dengan perubahan gradual dari variabel-variabel tersebut. Setelah ditransformasi log untuk menormalkan distribusinya, dilakukan uji ANOVA dan MANOVA untuk mengetahui signifikansi korelasi antara jarak dari tepi jalan dengan variabel mikroklimat dan vegetasi pohon. Variabel yang berkorelasi signifikan dengan jarak dari tepi jalan selanjutnya digunakan dalam analisis ordinasi PCA (Principle Component Analysis) untuk mengestimasi kedalaman efek tepi (depth of edge influence-DEI).

\section{HASIL PENELITIAN}

\section{Gradien Mikroklimat}

Semua variabel mikroklimat memperlihatkan perubahan gradual seiring dengan pertambahan jarak dari tepi ke interior hutan. Meskipun demikian terlihat adanya perbedaan pada masing-masing variabel dalam derajat perubahan serta jarak saat variabel tersebut mulai stabil nilainya (Gambar 1). Suhu udara, kecepatan angin dan intensitas cahaya mengalami penurunan yang nyata sampai jarak sekitar $40 \mathrm{~m}$ dari tepi jalan, sedangkan kelembaban udara relatif terus mengalami peningkatan sampai ke interior hutan. Hasil uji ANOVA dan MANOVA menunjukkan bahwa kesemua variabel mikroklimat berkorelasi signifikan dengan jarak dari tepi jalan (Tabel 1).

\section{Pola Vegetasi Pohon}

Meskipun variabel vegetasi pohon memperlihatkan kecenderungan perubahan gradual seiring dengan pertambahan jarak dari tepi ke interior hutan, namun nilainya bervariasi di sepanjang transek. Hal ini menunjukkan adanya variabilitas titik-titik sampel dalam pola vegetasi. Perubahan dalam variabel vegetasi umumnya terlihat sampai kedalaman $60 \mathrm{~m}$. Hasil uji ANOVA dan MANOVA menunjukkan bahwa hanya variabel tinggi pohon yang berkorelasi nyata dengan jarak dari tepi jalan.

Tabel 1. Hasil uji ANOVA dan MANOVA variabel mikroklimat dan vegetasi pohon terhadap jarak dari tepi jalan $\left({ }^{*} p<0.05\right.$, $* *$ $\left.p<0.01,{ }^{* *} p<0.001\right)$

\begin{tabular}{ccccc}
\hline Variabel & $\boldsymbol{F}$ & $\boldsymbol{p}$ & $\boldsymbol{r}^{\mathbf{2}}$ & $\boldsymbol{r}$ \\
\hline ANOVA & & & & -0.7663 \\
Suhu udara & 6.319 & $0.0036^{\star \star}$ & 0.5872 & 0.9009 \\
Kelembaban udara relatif & 23.568 & $0.0001^{\star \star \star *}$ & 0.8116 & -0.6437 \\
Kecepatan angin & 5.702 & $0.0063^{\star \star}$ & 0.4143 & -0.7363 \\
Intensitas cahaya & 4.143 & $0.0239^{\star}$ & 0.5421 & -0.6030 \\
Luas basal & 4.572 & 0.0650 & 0.3636 & 0.7413 \\
Tinggi pohon & 9.757 & $0.0142^{\star}$ & 0.5495 & 0.5979 \\
Jumlah jenis & 4.450 & 0.0679 & 0.3575 & 0.4544 \\
Kepadatan & 2.082 & 0.1871 & & \\
\hline MANOVA & & & &
\end{tabular}



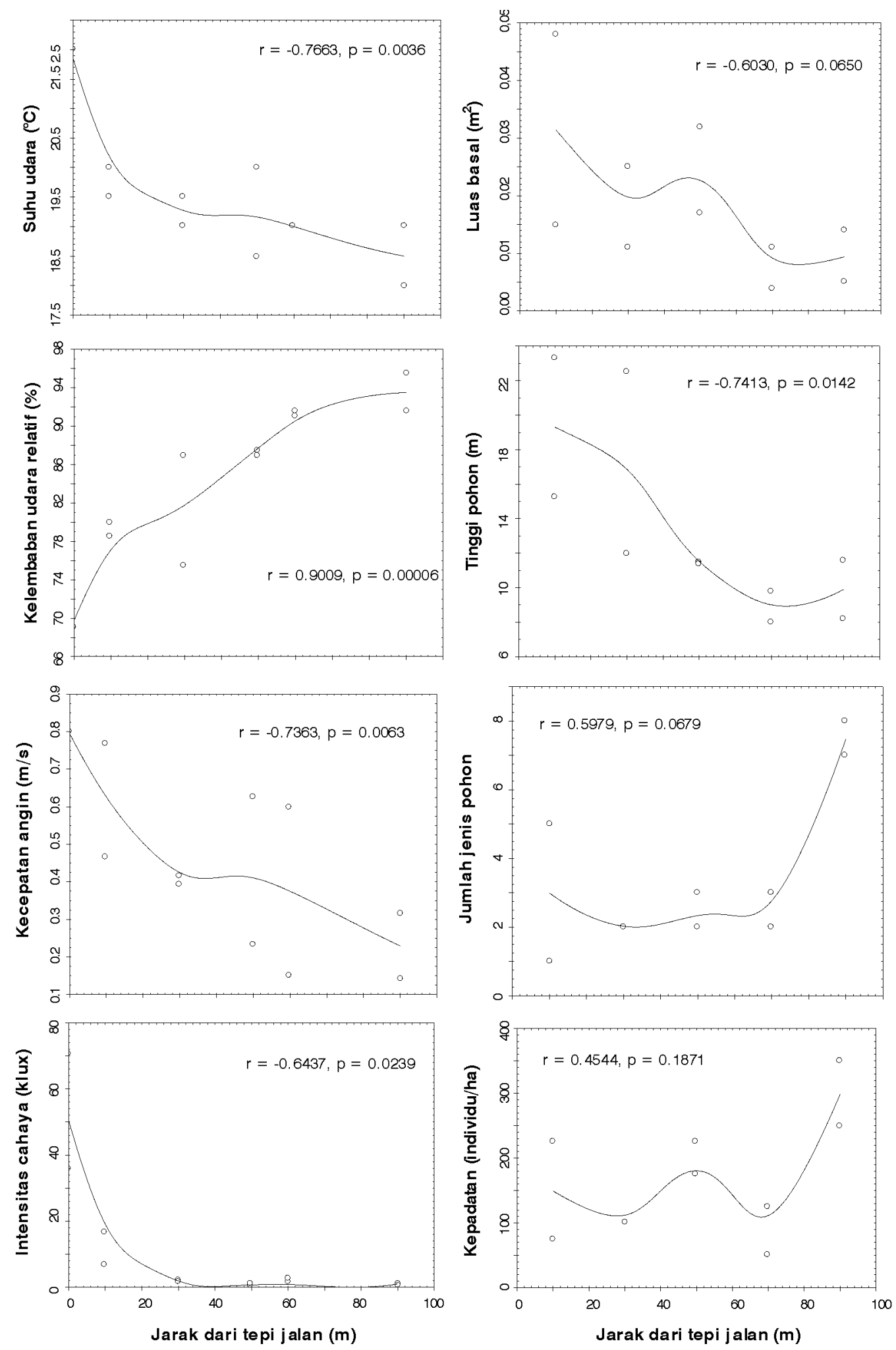

Gambar 1. Perubahan gradual mikroklimat dan pola vegetasi pohon di sepanjang transek $100 \mathrm{~m}$ dari tepi jalan ke interior hutan Bukit Pohen 


\section{PCA Berdasarkan Variabel Mikroklimat}

Berdasarkan hasil PCA, nilai eigenvalue untuk dua komponen pertama menjelaskan $63 \%$ dari variasi mikroklimat yang terjadi di hutan Bukit Pohen (Tabel 2). Stevens (1992) menyebutkan bahwa bobot variabel bermakna untuk suatu ukuran sampel apabila nilainya lebih dari 0.45 . Variabel mikroklimat yang berbobot besar pada sumbu PC I adalah intensitas cahaya (-), sedangkan variabel yang berbobot besar pada sumbu PC II adalah suhu udara (-), kelembaban udara relatif (-) dan kecepatan angin $(+)$. Titik-titik sampel diidentifikasi berdasarkan jarak dan diplotkan pada sumbu PC I dan PC II berdasarkan perbedaan dalam nilai variabel mikroklimat. Grafik PCA memperlihatkan adanya pengelompokan titik-titik sampel (Gambar 2). Titik-titik sampel yang berjarak kurang dari $40 \mathrm{~m}$ dari tepi jalan mengelompok di atas sumbu PC I dan mengindikasikan daerah dengan intensitas cahaya yang tinggi, suhu udara yang tinggi, kecepatan angin yang tinggi serta kelembaban udara yang rendah. Titik-titik sampel yang berjarak di atas $40 \mathrm{~m}$ mengelompok di bawah sumbu PC II dan mengindikasikan kondisi mikroklimat yang sebaliknya.

Tabel 2. Hasil Principal Component Analysis (PCA) dari variabel mikroklimat

\begin{tabular}{ccc}
\hline Komponen & $\mathbf{1}$ & $\mathbf{2}$ \\
\hline $\begin{array}{c}\text { Eigenvalue } \\
\text { \% kumulatif variansi yang } \\
\text { dijelaskan }\end{array}$ & 0.902 & 1.506 \\
\hline Bobot variabel & 22.6 & 63.0 \\
\hline Suhu udara & & \\
Kelembaban udara & 0.354 & -0.503 \\
Kecepatan angin & 0.354 & -0.503 \\
Intensitas cahaya & 0.494 & 0.524 \\
\hline
\end{tabular}

\section{PEMBAHASAN}

Koridor jalan yang melintasi hutan Bukit Pohen mempengaruhi kondisi mikroklimat pada tepi hutan yang berbatasan dengan jalan. Efek tepi terlihat dari gradien mikroklimat dari tepi ke interior hutan. Gradien intensitas cahaya sangat jelas di dekat tepi hutan. Matlack (1993) menyebutkan bahwa paparan cahaya matahari di daerah tepi merupakan pengontrol utama variabel mikroklimat lain seperti suhu udara dan kelembaban udara dan kelembaban tanah. Suhu udara, kelembaban udara, dan kecepatan angin di daerah tepi memperlihatkan gradien yang tidak begitu tajam dibandingkan intensitas cahaya. Hal ini menunjukkan bahwa ketiga variabel tersebut yang lebih mengontrol

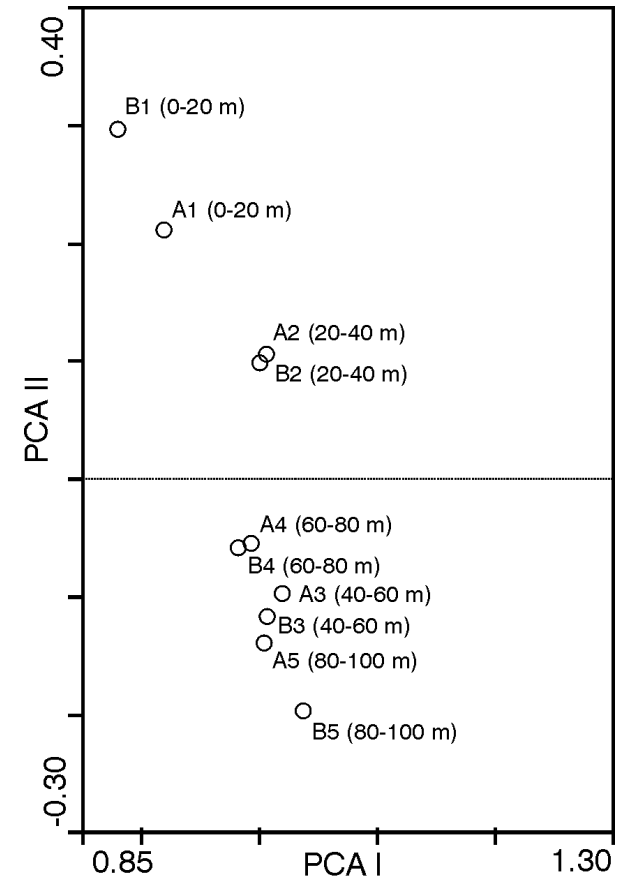

Gambar 2. Ordinasi PCA untuk setiap titik sampel berdasarkan variabel mikroklimat

kedalaman efek tepi serta perkembangan daerah tepi di hutan Bukit Pohen.

Pola vegetasi pohon di hutan Bukit Pohen cenderung tidak dikontrol oleh efek tepi, namun lebih dipengaruhi oleh faktor lain seperti adanya gangguan dan kegiatan penanaman. Tepi hutan di kawasan ini adalah kawasan hutan lindung yang merupakan hutan tanaman rasamala dengan usia tanam yang sama, sedangkan interiornya merupakan kawasan cagar alam yang hutannya pernah mengalami gangguan kebakaran di masa lampau dan saat ini tengah mengalami proses suksesi sekunder.

Berdasarkan analisis PCA, efek tepi terhadap mikroklimat terukur sampai kedalaman $40 \mathrm{~m}$ dari tepi jalan. Hasil ini sejalan dengan Young dan Mitchell (1994) serta Davies-Colley dkk. (2000) yang menemukan bahwa pengaruh tepi terhadap mikroklimat terukur sampai kedalaman 40-50 m pada fragmen hutan Podocarpus yang berbatasan dengan lahan terbuka.

Pengaruh tepi jalan yang terukur sampai kedalaman 40 $\mathrm{m}$ berimplikasi terhadap konservasi interior hutan di Bukit Pohen. Berdasarkan hasil penelitian, kami menyarankan agar hutan Bukit Pohen memiliki daerah penyangga dengan lebar sedikitnya $40 \mathrm{~m}$ untuk melindungi kondisi ekologis interior hutan dari perubahan mikroklimat akibat pembukaan jalan. 


\section{UCAPAN TERIMA KASIH}

Peneliti menyampaikan terima kasih kepada Kepala UPT-BKT Kebun Raya "Eka Karya" Bali yang telah memfasilitasi pelaksanaan penelitian, serta kepada tim kelompok penelitian ekologi Kebun Raya Bali yang membantu dalam pengambilan data di lapangan.

\section{KEPUSTAKAAN}

Chen J, Franklin JF, dan Spies TA, 1995. Growing-season microclimatic gradients from clearcut edges into oldgrowth Douglas-fir forests. Ecol. Appl. 5: 74-86.

Davies-Colley RJ, Payne GW, dan van Elswijk M, 2000. Microclimate gradients Across a forest edge. New Zealand Journal of Ecology 24(2): 111-121.

Forman RTT, 1995. Land Mosaics: The Ecology of Landscapes and Regions. Cambridge University Press, Cambridge. 87-90.
Gehlhausen SM, Schwartz MW, Augspurger CK, 2000. Vegetation and microclimatic edge effects in two mixed-mesophytic forest fragments. Plant Ecology 147: 21-35.

Harper KA, Macdonald SE, Burton PJ, Chen J, Brosofske KD, Saunders SC, Euskirchen ES, Roberts D, Jaiteh MS, dan Esseen PA, 2005. Edge Influence on Forest Structure and Composition in Fragmented Landscapes. Conservation Biology 19: 768-782.

Matlack GR, 1993. Microenvironment variation within and among forest edge sites in the eastern United States. Biol. Cons. 66: 185-194.

Stevens J, 1992. Applied Multivariate Statistics for the Social Sciences. 2nd ed. Lawrence Erlbaum Associates Publishers, New Jersey.

Young A, dan Mitchell N, 1994. Microclimate and vegetation edge effects in a fragmented podocarp-broadleaf forest in New Zealand. Biological Conservation 67: 63-72. 